\title{
Correction to: Morphological variation of fine root systems and leaves in primary and secondary tropical forests of Hainan Island, China
}

\author{
J. Aaron Hogan ${ }^{1} \cdot$ Oscar J. Valverde-Barrantes ${ }^{1} \cdot$ Qiong Ding $^{2} \cdot$ Han Xu $^{1,3} \cdot$ Christopher Baraloto $^{1}$
}

Received: 13 October 2020 / Accepted: 19 October 2020 / Published online: 26 November 2020

(c) INRAE and Springer-Verlag France SAS, part of Springer Nature 2020

\section{Correction to: Annals of Forest Science (2020) 77:76 https://doi.org/10.1007/s13595-020-00977-7}

This correction stands to correct the listed errors in the original article:

1. In the Abstract, under the Results subheading, a sentence reads: "From secondary to primary forests, mean root system diameter increased $0.4 \mathrm{~mm}$, mean specific root length decreased $3.5 \mathrm{~m} \mathrm{~kg}^{-1}$, and mean root system branching intensity decreased by 0.3 tips $\mathrm{cm}^{-1}$."

The authors request this be changed and noted as: "From secondary to primary forests, mean root system diameter increased $0.4 \mathrm{~mm}$, mean specific root length decreased $0.35 \mathrm{~m} \mathrm{~g}^{-1}$, and mean root system branching intensity decreased by 0.3 tips $\mathrm{cm}^{-1}$.

2. An error in the calculation of Specific Root Length (SRL) was identified, which resulted in the wrong units being presented in the published version. Thus, for the following paragraph found in the Results:

The online version of the original article can be online at https:// doi.org/10.1007/s13595-020-00977-7.

J. Aaron Hogan jhogan@fiu.edu

1 Department of Biological Sciences, International Center for Tropical Botany, Florida International University, Miami, FL 33199, USA

2 Research Center for Terrestrial Biodiversity of the South China Sea, Institute of Tropical Agriculture and Forestry, Hainan University, Haikou 570228, China

3 Research Institute of Tropical Forestry, Chinese Academy of Forestry, Longdong, Guangzhou 510520, China

\begin{abstract}
"Regarding root morphology, the predictedmarginal mean difference in SRL was on average about $3.5 \mathrm{~m} \mathrm{~kg}^{-1}$ greater in secondary than in primary forest (Fig. 4b). For example, in the secondary forest, values ranged from $26.0( \pm 1.9) \mathrm{m} \mathrm{kg}^{-1}$ for species in the Annonaceae to $78.3( \pm 1.1)$ for the Juglandaceae. In the primary forest, values ranged from 23.8 $( \pm 1.1) \mathrm{m} \mathrm{kg}^{-1}$ for species in the Annonaceae to 71.9 ( \pm 1.1$)$ for the Juglandaceae."
\end{abstract}

The authors request this be changed and noted as:

"Regarding root morphology, the predicted-marginal mean difference in SRL was on average about $0.35 \mathrm{~m} \mathrm{~g}^{-1}$ greater in secondary than in primary forest (Fig. 4b). For example, in the secondary forest, values ranged from $2.60( \pm 0.06) \mathrm{m} \mathrm{g}^{-1}$ for species in the Annonaceae to $7.83( \pm 0.06)$ for the Juglandaceae. In the primary forest, values ranged from $2.36( \pm 0.06) \mathrm{m} \mathrm{g}^{-1}$ for species in the Annonaceae to 7.17 ( \pm 0.06$)$ for the Juglandaceae."

3. The analysis of variance model for SRL was re-run, resulting in very minor changes. Thus, changes to the statistics for SRL in Table 2 are requested. The table in the published version reads:

\begin{tabular}{llllll}
\hline Trait (units) & Source & df & F & p & $\omega^{2}$ \\
\hline $\begin{array}{l}\text { Specific root length } \\
\left(\mathrm{m} \mathrm{kg}^{-1}\right)\end{array}$ & Species & 71 & 10.26 & $* * *$ & 0.238 \\
& Forest type & 1 & 7.10 & $* *$ & 0.002 \\
& $\begin{array}{l}\text { Species } \times \text { Forest } \\
\text { type }\end{array}$ & 58 & 3.58 & $* * *$ & 0.054 \\
& Residuals & 1818 & - & - & - \\
\hline
\end{tabular}

The authors request this be changed and noted as: 
Table 2 Analysis of variance table for linear models in the form: trait $\sim$ specieslfamily $\times$ forest type. Prior to model fitting, traits were $\log _{10}$ transformed in the case of leaf area, root diameter, SRL, root tissue density, and root branching intensity to improve data normality

\begin{tabular}{llllll}
\hline Trait (units) & Source & df & F & p & $\omega^{2}$ \\
\hline Specific root length $\left(\mathrm{m} \mathrm{g}^{-1}\right)$ & Species & 71 & 10.19 & $* * *$ & $* .237$ \\
& Forest type & 1 & 7.64 & $* .002$ \\
& Species $\times$ Forest type & 58 & 3.58 & $* * *$ & 0.054 \\
& Residuals & 1818 & - & - & - \\
\hline
\end{tabular}

${ }^{*} p<0.05, * * p<0.01, * * * p<0.001$

${ }^{a}$ Effect size $=\omega^{2}$, effect size $\left(\omega^{2}\right)$ values near 0.01 are considered small, near 0.06 are considered medium, and near 0.14 are considered large. $d f$ degrees of freedom

4. The units in Fig. 4b for SRL are incorrect in the published version. There was also an error in the units label for Fig. 4c, however this was just a typo, and not calculation error. The authors request this be changed to this revised figure (filename: "Fig. 4_ERRATUM.tiff”):

5. Linear regression models presented in Table 3 were rerun, again, resulting in very minor changes. Model slopes $(\beta)$, standard error (se), and root-mean-squared error, all changed by a factor or 10 . Thus the following minor changes to the statistics for SRL in Table 3 are requested. The table in the published version reads:
6. The units in Fig. 5c for SRL are incorrect in the published version. The authors request this be changed to this revised figure (filename: “Fig. 5_ERRATUM.tiff”)
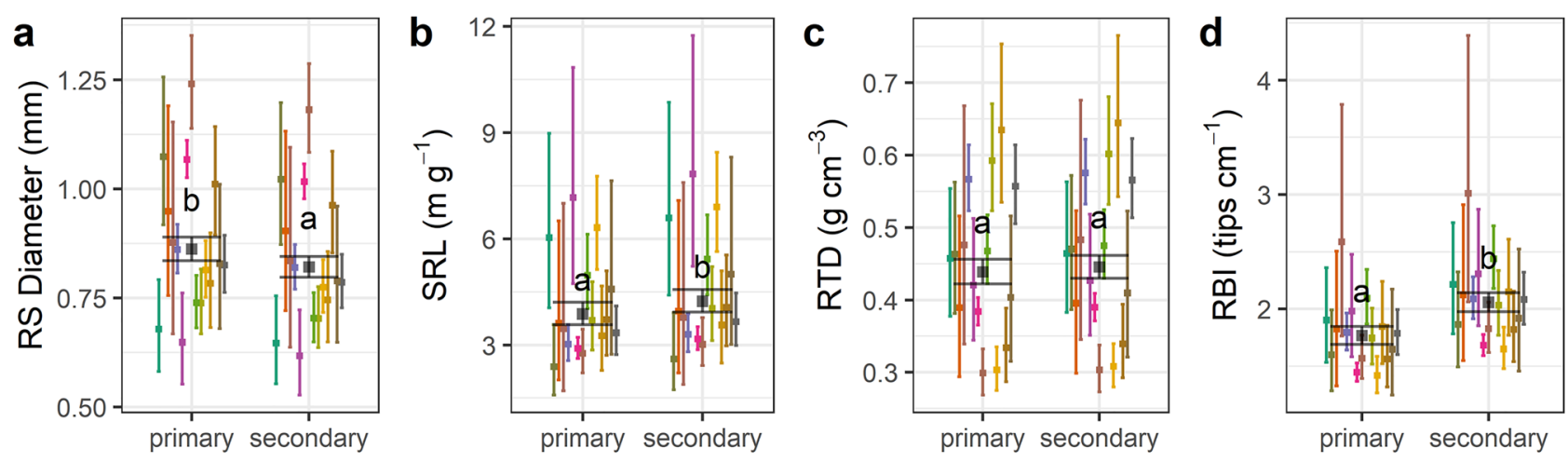

\begin{tabular}{|c|c|c|c|c|c|c|c|c|}
\hline Trait (units) & Forest type & $\begin{array}{l}\text { Variable } \\
\text { (units) }\end{array}$ & $\beta$ & se & $P$ & $F(1,148)$ & $R^{2}$ & RMSE \\
\hline \multirow{4}{*}{$\begin{array}{l}\text { Specific root } \\
\text { length (m } \\
\left.\mathrm{kg}^{-1}\right)\end{array}$} & Secondary & Soil BS (\%) & 0.262 & 0.188 & n.s & 1.94 & 0.01 & 31.14 \\
\hline & Primary & & 1.171 & 0.551 & $*$ & 4.53 & 0.03 & 33.79 \\
\hline & Secondary & Soil P $\left(\mathrm{g} \mathrm{kg}^{-1}\right)$ & 23.42 & 84.80 & n.s & 0.08 & $<0.01$ & 31.33 \\
\hline & Primary & & 324.07 & 128.32 & $*$ & 6.38 & 0.04 & 33.58 \\
\hline
\end{tabular}

The authors request this be changed and noted as: 
Table 3 Regression results from least-squares linear models in the form of trait $\sim$ variable. Table to accompany Fig. 5. Models were fit separately by forest type

\begin{tabular}{lllllllll}
\hline Trait (units) & Forest type & Variable (units) & \multicolumn{1}{l}{$\beta$} & \multicolumn{1}{l}{$S e$} & $P$ & $F(1,148)$ & $R^{2}$ & RMSE \\
\hline Specific root length $\left(\mathrm{m} \mathrm{g}^{-1}\right)$ & Secondary & Soil BS (\%) & 0.026 & 0.018 & $n . s$ & 1.94 & 0.013 .11 \\
& Primary & & 0.117 & 0.055 & $*$ & 4.53 & 0.03 & 3.38 \\
& Secondary & Soil P $\left(\mathrm{g} \mathrm{kg}^{-1}\right)$ & 2.34 & 8.48 & $n . s$ & 0.08 & $<0.013 .13$ \\
& Primary & & 32.41 & 12.83 & $*$ & 6.38 & 0.04 & 3.36 \\
\hline
\end{tabular}

${ }^{*} p<0.05, * * p<0.01, * * * p<0.001$

${ }^{a}$ Model coefficient estimates $(\beta)$, standard errors $(s e)$, and associated probabilities $(p)$ are given for each variable by forest type (intercept terms are not shown). Regression F-statistics $(F)$ and coefficients of determination $\left(R^{2}\right)$ and root-mean-squared error (RMSE) are given for each model. The $F(1,148)$ critical value at $\alpha=0.05$ is 3.905. Italicized model coefficients show significant ANCOVA interaction terms between forest type and soil variable $(p<0.05)$. n.s. non-significant, Probabilities are denoted as follows:

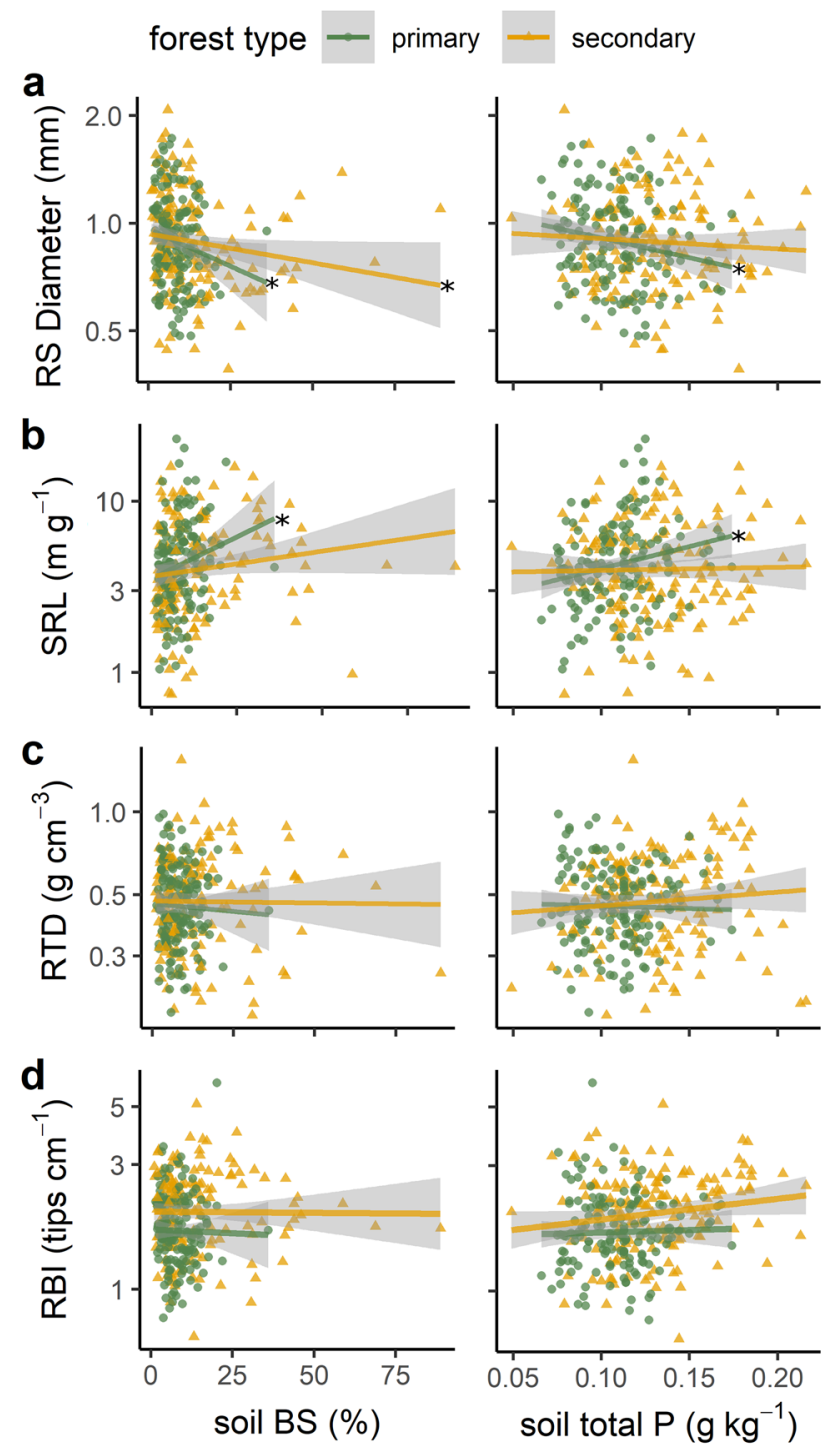

7. In the List of abbreviated terms:

The units for SRL (Specific Root Length) were given as "m kg $\mathrm{kg}^{-1}$ ", which is incorrect.

The authors request this be changed to: " $\mathrm{m} \mathrm{g}^{-1}$ ". 